\title{
Price competition and nominal illusion: experimental evidence and a behavioural model
}

\author{
Antonio J. Morales ${ }^{1}$ (D) Enrique Fatas ${ }^{2,3}$
}

Received: 7 June 2020 / Accepted: 7 May 2021 / Published online: 8 June 2021

(c) The Author(s) 2021

\begin{abstract}
The standard approach to nominal illusion in Economics sees it as a transitory phenomenon, as economic agents eventually see through the nominal veil, making the right choices. Recent empirical studies suggest that money illusion may persist, distorting real prices in a variety of economic environments, including the housing market and the stock market. In this paper, we explore the emergence and persistence of nominal illusion in an experimental entry game where firms must choose which local market to enter, and then compete in prices. All local markets are equivalent in real terms and they only differ in the currency the price competition is run under. Our experimental results show a positive, persistent and monotone effect of the nominal exchange rate on market prices, statistically significant for large enough exchange rate. We provide an explanation in terms of players simplifying the choice set using discrete grids.
\end{abstract}

Keywords Price competition · Money illusion · Experiments $\cdot$ Nominal representation

JEL Classification C72 · C9 · D43 · L13

\footnotetext{
Antonio J. Morales

a.morales@uma.es

Enrique Fatas

efatas@upenn.edu; efatas@icesi.edu.co

1 Smart Decision Lab, Universidad de Málaga, Málaga, Spain

2 Center for Social Norms and Behavioral Dynamics, University of Pennsylvania, Philadelphia, USA

3 Escuela de Admnistración, Universidad ICESI, Valle del Cauca, Colombia
} 


\section{Introduction}

Humans are not immune to psychological biases when taking economic decisions (see Kahneman 2003; Thaler 2000). One such bias, money illusion, was first defined in Fisher (1928) as the "failure to perceive that the dollar, or any other unit of money, expands or shrinks in value". This tendency of people to think of money in nominal, rather than real terms has been widely documented ${ }^{1}$; although until recently (Tyran 2007), it has played only a limited role in explaining economically relevant behaviour. Recent empirical papers document how money illusion may persistently mediate inflation and drive real prices in a variety of economic environments, including the housing market (Brunnermeier and Julliard 2008) and the stock market (Cohen et al. 2005; Acker and Duck 2013).

The standard view in economics is that nominal illusion is a transitory phenomenon. Economic agents will eventually see through the nominal veil and will start making the right choices. Implicit in this argument is that nominal illusion entails a cost, because nominal and real payoffs are not aligned. It is, however, common to come across situations where nominal and real payoffs are perfectly aligned, as it happens when choices are done using different currencies, and nominal illusion is transient. For example, one of the most studied cases is the changeover to the Euro in the European Economic and Monetary Union in 2002. The overall conclusion is that money illusion happened and it was transitory (see for example Kooreman et al. 2004; Cannon and Cipriani 2006 and more recently Bittschy and Duppel 2015).

The transience of nominal illusion seems a well-established fact in the economic literature. In this paper, we show that nominal illusion persists in competitive price settings. The basic intuition is that in a competitive setting, nominal illusion may facilitate collusion and once firms are making extraordinary profits, they have no incentives to modify their behaviour.

We present experimental data from a one-shot entry game where players must decide in which of three markets to enter. Once the entry decision is done, players compete in prices for 20 periods in a standard static, full information, Bertrand duopoly game. The interesting twist is that all markets are equivalent, meaning that they are but different nominal representations of the same economy, e.g. all markets are identical in real terms and only differ in the local currency in which prices are nominated.

We find that subjects spread evenly among the three local markets, which is consistent with the prediction yielded by all markets being identical in real terms. But when we compare pricing behaviour across different nominal representations, we find a positive correlation between posted prices and nominal exchange rates: coarser currencies are associated with higher prices. For large enough exchange rate, this pattern becomes statistically significant. Even more, this monotone nominal illusion is of a permanent nature as there is no convergence to the Nash prices: prices stay consistently high without declining to the Nash equilibrium prices.

\footnotetext{
1 Early evidence about the effects of money illusion came from individual decision-making. Shafir et al (1997) report the results of survey questions designed to assess people reaction to changes in income and prices. They find that although subjects recognize that in the economic transactions, elements of both nominal and real representations are important, the fact that the nominal representation is simpler and more salient makes them to focus more on the nominal one, originating the phenomenon of the money illusion.
} 
Most experimental papers on money illusion consider situations where nominal and real payoffs are not aligned, as in Fehr and Tyran (2001, 2007, 2014), that report transient money illusion. Fehr and Tyran (2008) and Noussair et al. (2012) compare prices before and after a nominal shock, and report a pronounced inertia in the convergence to the unaltered (in real terms) equilibrium, although the rate of convergence depends on whether the shock is positive or negative (Noussair et al. 2012), or whether actions are strategic complements or substitutes (Fehr and Tyran 2001). There is only one instance in which a temporary money illusion phenomenon has a permanent effect. Fehr and Tyran (2007) consider a price competition game with three Pareto ranked equilibria and two treatments: one in which the payoff matrix is presented in nominal terms and other in which it is presented in real terms. By design, the payoff-dominant equilibrium in nominal terms is the payoff-dominated equilibrium in real terms. They find that in the condition in which payoff information is provided in real terms, subjects quickly converge to the Pareto-dominant equilibrium whereas when the payoff information is provided in nominal terms, subjects coordinate on the equilibrium that provides them with the highest nominal payoff (but the lowest real payoff). Money illusion, although temporary in nature, has permanent effects because when players finally see through the nominal veil, it is too late to get away from the "bad" equilibrium. Thus, those players suffering from the illusion effect end up worse off. In our setting, the Nash equilibria are also Pareto ranked, but their ranking is the same regardless of whether information is provided in real or nominal terms. In addition, we show that different nominal representations select different Nash equilibria.

Closer to our paper, Eisenhuth (2017) analyses the market survival of moneyillusioned economic agents in a dynamic financial market model populated by rational economic agents. Eisenhuth (2017) shows that market forces can wipe out rational agents in the long run, leaving a market full of money-illusioned agents. In our experiment, we find a result similar in spirit: in the long run, all local markets are populated by money-illusioned firms. Our proposed mechanism is though different: if economic agents start focusing on the nominal representations because they are simpler and more salient (as it is the standard view in the literature, see for example Shafir et al. 1997), and they keep using them because it is a very profitable strategy, then competitive forces are simply perpetuating collusive practices. We propose a behavioural model that rationalizes the monotone money illusion based on participants choosing grids as a simplifying procedure.

The rest of the paper is as follows. Section 2 presents the experimental design, procedures and hypotheses. Experimental results are discussed in Sect. 3. Section 4 presents the behavioural model and finally, Sect. 5 concludes.

\section{Experimental design, procedures and hypotheses.}

\subsection{Experimental design}

Our experiment consists of one treatment-an entry game followed by a price competition game-and two sessions. See Table 1 for the details. 
Table 1 Experimental design

\begin{tabular}{llll}
\hline Local market & \multicolumn{4}{l}{ Nominal representation of the economy } \\
\cline { 2 - 4 } & M100 & M20 & M5 \\
\hline Local currency & Titanio & Methanio & Daphnio \\
Exchange rate to & $1: 5$ & $1: 25$ & $1: 100$ \\
$\quad$ ECU & & & \\
Matching & Partners & Partners & Partners \\
Price range & {$[0.0,100.0]$} & {$[0.00,20.00]$} & {$[0.000,5.000]$} \\
Decimal places & 1 & 2 & 3 \\
\hline
\end{tabular}

In the entry game, experimental subjects had to choose in which local market they wished to compete. Local markets are characterized by their local currencies, each featuring a different exchange rate to ECU, the experimental currency units. Price competition takes the form of symmetric duopolies with quadratic cost function $c$ $(q)=c q^{2}$ with $c>0$ and fixed demand $Q>0$. In each duopoly, the lowest price firm will serve the whole market and that the demand is split in case of a tie. The set of Nash equilibrium prices is the interval $\left[\frac{c Q}{2}, \frac{3 c Q}{2}\right]$.

Fatas et al. (2014) run experimental sessions with the parametrization $c=5, Q=$ 20 and $P=500$, and prices nominated in ECUS, and find that market prices converge to the Pareto efficient NE price 150. In our experiment, we make experimental subjects to choose between three different nominal representations of the base economy considered in Fatas et al. (2014), characterized by different exchange rates of the local currencies to ECU. The three nominal representations are named M100, M20 and M5, and the exchange rates are $e=5,25$ and 100, respectively. The exchange rate is simply the number of ECU per unit of the local currency.

We made two adjustments to the three nominal representations for experimental subjects to face equivalent payoff matrices. First, the largest admissible price $P^{*}$ was deflated $P^{*}=P / e$; so as to keep the maximum profit the same across nominal representations. Second, we adjusted the number of decimal places that experimental subjects could use so the cardinality of the strategy space across nominal representations has the same order of magnitude. ${ }^{2}$ Finally, note that the local markets are named after the largest admissible price: for example, the largest price available in the market M20 is $500 / 25=20$.

Note that the addition of decimal spaces in our setting more than offset the maximum price scaling. Alternative nominal representations like $[0,500],[0.0,50.0]$ and $[0.00$, 5.00] would have kept the number of prices, fully preserving cardinality. We decided to give participants a choice between more than two markets, so we opted for a different design choice with three alternative markets. As the number of prices in our nominal representations M5, M20 and M100 decreases with the exchange rate, we hypothesize that competitive undercutting should be easier in M5 than in M20, or M100, making our experiment a stronger test.

\footnotetext{
2 The cardinality of the strategy space is 1001 for M100, 2001 for M20 and 5001 for M5.
} 
The entry decision that experimental subjects had to take is in which of the three local markets (M100, M20 and M5) to enter; subsequently, subjects were randomly matched (under a partner protocol) to compete in a duopoly for 20 rounds among those who selected the same market. Subjects were explicitly told in the instructions that the demand and costs conditions across the different local markets were identical (although they were never informed of the parameter values of the demand and cost function, and the precise form of the decreasing returns to scale) and that the exchange rates that were used to convert profits from the local currency to Euros were such that "your potential benefits are also identical in the three markets".

Note that in our design participants self-selected into one of the three local markets. Because nominal illusion is a phenomenon that arises out of simplicity and accessibility of the nominal representation as compared to the real representation, we opted for letting experimental subjects choose the nominal representation in the belief that they would choose the one they felt more comfortable with. This way, we would maximise the chance of having money illusion in the laboratory. One could argue that this introduces a minimal group paradigm into our design, making individuals in one local market more willing to cooperate (or collude) with others. Even though we cannot exclude the possibility that group identity might raise prices in any local market, it could not explain differences between the three local markets. Moreover, minimal group identities are a highly context-dependent paradigm, with weaker effects in competitive environments (see Buchan et al. 2009, 2011).

At the end of each round, each subject was informed of their choice, their rival's choice and their profits and the rival's profit. A table displaying past choices and profits was also available.

\subsection{Experimental procedures}

Experiments were run in the laboratory for research in experimental economics at the University of Valencia. Eighty students (forty duopolies) from business and economics were recruited using a standard electronic recruitment procedure. Experimental subjects received the accumulated payoffs from all the rounds in the experiment. Two sessions were run and subjects earned $12 €$ on average (plus the $€ 5$ show-up fee) for an experiment that lasted for less than an hour. A set of instructions translated from the Spanish is available in the Appendix.

Hypotheses Experimental subjects had to make two types of decisions in this experiment. First, the local currency in which they wanted to set the prices and then the pricing strategy over a period of 20 rounds. Our null hypotheses will be based on rational play, characterized by the notion of subgame perfect Nash equilibrium. For alternative hypotheses, the reader is referred to Sect. 4.

In stage 2, and once participants had chosen a market, they were matched in pairs to compete in prices for 20 rounds with the same opponent. Because the local markets are equivalent in real terms, and the null hypothesis is based on the concept of Nash equilibrium, that is not prone to money illusion, the null hypothesis is that pricing behaviour across the local markets is similar. 
Hypothesis 1 Similar pricing behaviour (in real terms) across the local markets.

We now apply backward induction and consider stage 1, the entry decision. Because the local markets are equivalent in real terms, the null hypothesis is that players are indifferent between choosing any local market.

Hypothesis 2 Equal entry in the local markets.

\section{Experimental results}

In this section, we present some summary descriptive statistics to compare average behaviour across nominal representations. We later perform a welfare analysis.

\subsection{Entry decisions}

In the experimental entry game, the first task that subjects faced was precisely in which market they wanted to interact. Out of the 80 participants, 32 chose M100, 24 chose M20 and another 24 subjects chose M5. A chi-square test expecting equal frequencies does not reject the null hypothesis of equal entry in the three local markets (Pearson $\operatorname{chi}^{2}(2)=1.6000, p=0.449$ ). Hence, from a behavioural point of view, the three nominal representations were equally appealing to experimental subjects.

Result 1 There is no nominal representation superior to any other in attracting the attention of experimental subjects.

\subsection{Pricing decisions}

Table 2 contains some descriptive statistics of posted and market prices across local markets. They are expressed in ECUS so comparison between local markets is easier.

This table reveals that in the first period, posted and market prices for the three local markets are significantly larger than the Nash prediction ${ }^{3}$ (the efficient NE is 150), they are located slightly above the midpoint of the pricing interval (the largest admissible price is 500) and that the differences among them are not statistically significant, confirming the rationale behind the equal entry hypothesis. ${ }^{4}$ However, as competition evolves, a clear ordering in the average price dimension-specially marked in the last five periods - emerges: larger average prices are associated with larger exchange rates, well above the efficient NE. ${ }^{5}$ This is in sharp contrast to what it is hypothesized

\footnotetext{
3 Wilcoxon sign tests reject the null hypothesis that the median price equals the Nash efficient equilibrium (the $p$ values for all treatments is $<0.0000$ ). We use only one observation per market or individual, averaging all posted (market) prices for the same individual (market) across the 20 rounds.

4 Mann-Whitney tests for pairwise comparisons of posted prices in period 1 are not statistically different at the standard 5\% level (even when posted prices are marginally higher in M5 than in M20 in period 1).

5 Mann-Whitney tests for pairwise comparisons reveals that the comparison M5-M100 is statistically significant at the 10\% level ( $p$ value $=0.0947)$, while other comparisons are not $(p$ values $=0.210$ for M5 versus M20 and $p$ value $=0.298$ for M20 versus M100). Later in the paper, we complement this analysis with econometric analysis.
} 
Table 2 Average prices by nominal representation

\begin{tabular}{|c|c|c|c|c|c|c|c|c|}
\hline \multirow[t]{3}{*}{ Market } & \multirow[t]{3}{*}{ Obs. (i) } & \multicolumn{3}{|c|}{ Posted prices } & \multirow[t]{3}{*}{ Obs. (m) } & \multicolumn{3}{|c|}{ Market prices } \\
\hline & & \multicolumn{3}{|l|}{ Periods } & & \multicolumn{3}{|l|}{ Periods } \\
\hline & & First & All & Last 5 & & First & All & Last 5 \\
\hline M100 & 640 & $\begin{array}{c}265.86 \\
(115.65)\end{array}$ & $\begin{array}{c}238.09 \\
(142.51)\end{array}$ & $\begin{array}{c}221.94 \\
(142.84)\end{array}$ & 320 & $\begin{array}{l}212.81 \\
(72.03)\end{array}$ & $\begin{array}{c}215.15 \\
(137.66)\end{array}$ & $\begin{array}{c}200.74 \\
(134.30)\end{array}$ \\
\hline M20 & 480 & $\begin{array}{l}294.96 \\
(78.02)\end{array}$ & $\begin{array}{l}247.70 \\
(98.57)\end{array}$ & $\begin{array}{c}256.05 \\
(120.47)\end{array}$ & 240 & $\begin{array}{l}252.10 \\
(35.29)\end{array}$ & $\begin{array}{l}224.29 \\
(85.21)\end{array}$ & $\begin{array}{c}244.67 \\
(123.36)\end{array}$ \\
\hline M5 & 480 & $\begin{array}{c}282.33 \\
(109.42)\end{array}$ & $\begin{array}{c}305.14 \\
(141.37)\end{array}$ & $\begin{array}{c}304.45 \\
(152.04)\end{array}$ & 240 & $\begin{array}{l}232.96 \\
(83.79)\end{array}$ & $\begin{array}{c}290.56 \\
(142.81)\end{array}$ & $\begin{array}{c}296.14 \\
(153.18)\end{array}$ \\
\hline
\end{tabular}

Standard deviations in parentheses

Obs (i) $=$ Number of individual observations (number of subjects $\times$ number of periods)

Obs $(\mathrm{m})=$ Number of market observations (number of markets $\times$ number of periods)

in Hypothesis 1. Our analysis rejects the universal validity of the Nash predictions across nominal representations and shows a positive relation between exchange rates and average prices. ${ }^{6}$

Result 2 Hypothesis 1 is rejected, as prices follow a monotone money illusion effect. Market prices are above Nash predictions in all local markets and prices increase with the nominal exchange rate. Nonparametric tests reveal that the effect is statistically significant only for large enough exchange rates (as in M5).

Table 2 also shows that the money illusion effect does not disappear over time. If it were temporary, we would see a decline in prices towards the Nash equilibrium values as time passes, however, average prices for the last five rounds are much higher than the Nash equilibrium prices (150).

Figure 1 displays the time evolution of average market prices by nominal representation. Visual inspection reveals no noticeable negative trend in any treatment. For nonparametric analysis, we run Jonckheere trend tests (also known as Jonckheere-Terpstra), and find that trends are not significant for M5 and M100 $(J=14045.5$, $p$ value $=0.5536$ and $J=23,095, p$ value $=0.1988$, respectively). The Jonckheere trend test reveals a significant and negative trend in M20 $(J=12,319, p$ value $=$ 0.0140 ). Table 3 investigates nonlinearities running a trend analysis for each treatment, where the dependent variable is the market price (one observation per market and period). The analysis allows for quadratic specifications of the variable Period to account for nonlinear trends in any treatment, and particularly in treatment M20. In models without the quadratic term, the variable Period is never significant. The quadratic specification reconciles parametric and nonparametric analysis for treatment M20. When the quadratic term is included, treatment M20 has a significant

\footnotetext{
${ }^{6}$ The existence of prices above competitive levels is a well-known phenomenon in experimental Bertrand games, Dufwenberg and Gneezy (2000) documents over-competitive prices in linear Bertrand games. Fatas et al. $(2005,2007,2013)$ show how linear Bertrand games may significantly deviate from the competitive outcome when tacit collusion is facilitated by market features (e.g. price guarantees). None of these papers is consistent with the monotone effect of nominal representations discussed below.
} 


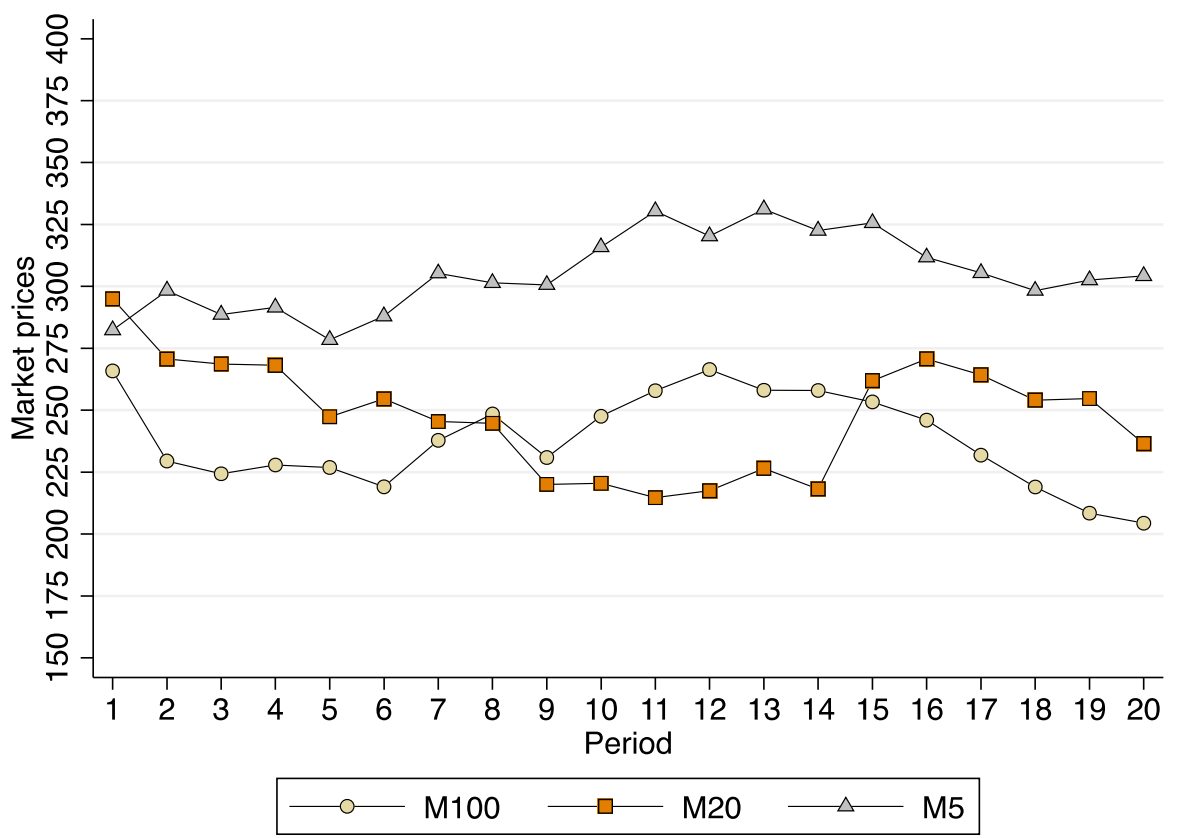

Fig. 1 Evolution of average market prices by nominal representation

Table 3 Trends for average market prices by nominal representation OLS estimations

\begin{tabular}{lllllll}
\hline & $(1)$ & $(2)$ & $(3)$ & $(4)$ & $(5)$ & $(6)$ \\
& M5 & M5 & M20 & M20 & M100 & M100 \\
\hline Period & 2.511 & $12.04^{*}$ & 0.177 & $-9.654^{* *}$ & 0.133 & 8.963 \\
& $(1.595)$ & $(6.697)$ & $(0.957)$ & $(3.981)$ & $(1.338)$ & $(5.614)$ \\
Period squared & & -0.454 & & $0.468^{* *}$ & & -0.420 \\
& & $(0.310)$ & & $(0.184)$ & & $(0.260)$ \\
Constant & $264.2^{* * *}$ & $229.2^{* * *}$ & $222.4^{* * *}$ & $258.5^{* * *}$ & $213.8^{* * *}$ & $181.4^{* * *}$ \\
& $(19.11)$ & $(30.54)$ & $(11.46)$ & $(18.15)$ & $(16.02)$ & $(25.60)$ \\
Observations & 240 & 240 & 240 & 240 & 320 & 320 \\
$R$-squared & 0.010 & 0.019 & 0.000 & 0.027 & 0.000 & 0.008 \\
\hline
\end{tabular}

Standard errors in parentheses

$* * * p<0.01 ; * * p<0.05 ; * p<0.1$

convex trend, implying a negative trend for a few periods - up to period 10, followed by a positive trend, as market prices start to increase over time. Model (4) suggests that once nonlinearities are considered, there is no convergence to Nash prices in M20. ${ }^{7}$

\footnotetext{
7 As an illustration, Model (4) in Table 3 predicts an average market price of 225 for the last ten periods and an average market price of 223 for the first ten ones, in line with the observed data (225 and 224, respectively). 
Table 4 Posted prices across nominal representations. Panel data estimations

\begin{tabular}{|c|c|c|c|c|c|}
\hline & (1) & (2) & (3) & (4) & (5) \\
\hline Period & $\begin{array}{l}1.010 \\
(2.324)\end{array}$ & $\begin{array}{l}-0.965 \\
(2.080)\end{array}$ & $\begin{array}{l}3.696 * * * \\
(1.245)\end{array}$ & $\begin{array}{l}3.700 * * * \\
(1.198)\end{array}$ & $\begin{array}{l}2.862^{* *} \\
(1.215)\end{array}$ \\
\hline Period squared & $\begin{array}{l}-0.0559 \\
(0.106)\end{array}$ & $\begin{array}{l}-0.0120 \\
(0.0936)\end{array}$ & $\begin{array}{l}-0.166^{* * *} \\
(0.0534)\end{array}$ & $\begin{array}{l}-0.167 * * * \\
(0.0507)\end{array}$ & $\begin{array}{l}-0.140^{* * *} \\
(0.0515)\end{array}$ \\
\hline M5 & $\begin{array}{l}67.05^{* *} \\
(34.12)\end{array}$ & $\begin{array}{l}53.79 * * \\
(23.97)\end{array}$ & $\begin{array}{l}11.53^{* *} \\
(5.276)\end{array}$ & $\begin{array}{l}6.814 * \\
(3.865)\end{array}$ & $\begin{array}{l}7.919 * * \\
(3.597)\end{array}$ \\
\hline M20 & $\begin{array}{l}9.623 \\
(26.41)\end{array}$ & $\begin{array}{l}26.22 \\
(20.70)\end{array}$ & $\begin{array}{l}1.081 \\
(3.985)\end{array}$ & $\begin{array}{l}0.472 \\
(3.778)\end{array}$ & $\begin{array}{l}4.182 \\
(4.046)\end{array}$ \\
\hline Collusion in $t-1$ & & $\begin{array}{l}171.9 * * * \\
(16.17)\end{array}$ & & & $\begin{array}{l}31.15 * * * \\
(6.894)\end{array}$ \\
\hline Own price in $t-1$ & & & $\begin{array}{l}0.891 * * * \\
(0.0217)\end{array}$ & $\begin{array}{l}0.534 * * * \\
(0.0453)\end{array}$ & $\begin{array}{l}0.500 * * * \\
(0.0455)\end{array}$ \\
\hline Rival's price in $t-1$ & & & & $\begin{array}{l}0.429 * * * \\
(0.0451)\end{array}$ & $\begin{array}{l}0.401 * * * \\
(0.0442)\end{array}$ \\
\hline Constant & $\begin{array}{l}235.5^{* * * *} \\
(21.20)\end{array}$ & $\begin{array}{l}225.0 * * * \\
(16.63)\end{array}$ & $\begin{array}{l}7.457 \\
(7.657)\end{array}$ & $\begin{array}{l}-9.827 \\
(6.326)\end{array}$ & $\begin{array}{l}5.590 \\
(7.236)\end{array}$ \\
\hline M5-M20 & $\begin{array}{l}57.429 * * \\
(29.055)\end{array}$ & $\begin{array}{l}27.570 \\
(22.949)\end{array}$ & $\begin{array}{l}10.448 * * \\
(4.531)\end{array}$ & $\begin{array}{l}6.341^{*} \\
(3.449)\end{array}$ & $\begin{array}{l}3.737 \\
(3.436)\end{array}$ \\
\hline$R$-squared (between) & 0.0640 & 0.6354 & 0.9954 & 0.9898 & 0.9901 \\
\hline Observations & 1600 & 1520 & 1520 & 1520 & 1520 \\
\hline
\end{tabular}

Robust standard errors in parentheses

$* * * p<0.01 ; * * p<0.05 ; * p<0.1$

Result 3 The monotone money illusion effect does not vanish over time (with the exception of M20), and market prices do not converge to Nash Equilibrium prices.

Panel data estimations are displayed in Table 4 and confirm the conclusions drawn from the graphical analysis and parametric and nonparametric analysis. We take one observation per firm and period; observations are clustered by market. The dependent variable is the posted price of a firm in a period and the independent variables are dummy variables for the local markets M5 and M20 (the omitted market is M100), a quadratic specification for the variable Period and three variables that control for the decisions of participants in the previous round: (1) collusion, a dummy variable that takes value 1 if the two participants set the same price and (2) own and rival's posted prices.

Model (1) does not include any control and shows that the variables Period and Squared Period are not statistically significant. The dummy variable for nominal representation M5 is positive and statistically significant, confirming that posted prices in treatment M5 are significantly larger than in the omitted treatment M100. The dummy variable for M20 is also positive but not statistically significant, suggesting that the exchange rate must be high enough to observe evidence of monotone money illusion in the laboratory. The test of equality of the estimators of the dummy variables to 


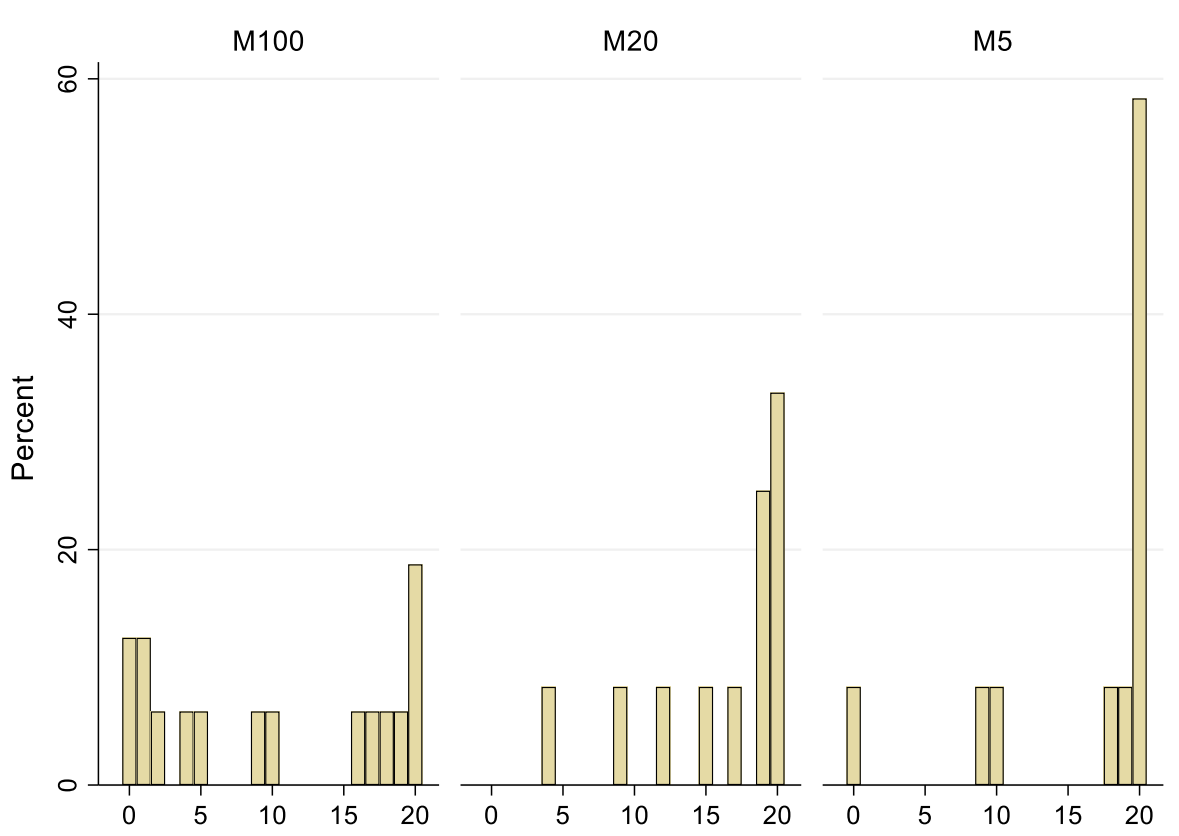

Fig. 2 Distribution of the number of periods with overprice by each local market by nominal representation

compare M5 and M20 shows that the coefficient of variable M5 is significantly higher than the coefficient of the dummy M20. ${ }^{8}$ Controlling for participants' decisions in the previous round does not change the sign of the coefficients (now there is a significant and positive time trend) although as it is discussed in Achen (2000), it increases the overall fitness of the model at the cost of suppressing the explanatory power of other independent variables, i.e. treatment variables.

We finally study the heterogeneity in the money illusion effect. We compute for each market, the percentage of periods with market prices above the interval of Nash equilibria. Figure 2 displays, for each nominal representation, the distribution of markets by the number of periods with overpricing.

We find that the larger the exchange rate, the distribution of markets by rounds with overpricing is more skewed to the right, e.g. the number of markets with prices above the Nash equilibrium interval increases with the exchange rate. Hence, the monotone money illusion is not an artefact arising from the aggregation of behaviour. ${ }^{9}$

\footnotetext{
8 We understand that the test of equality of the estimators of the dummy variables M5 and M20 is a second best to test for differences between treatments M5 and M20. Table 9 in the Appendix reproduces the analysis from Table 4 but setting M5 as the omitted treatment. This allows for a direct comparison between M5 and M20. We find that the coefficient for the dummy variable M20 is always negative and statistically different from zero in 3 of the 5 models.

9 On aggregate, the percentage of market prices above Nash is $50.62 \%, 80.83 \%$ and $81.66 \%$ in M100, M20 and M5, respectively, and the pairwise comparisons between M100 (50.62\%) and M20 and M5 (80.83\% and $81.66 \%$, respectively) are strongly significant (two sided Fisher exact test $p$ value $<0.0000$ ).
} 
Table 5 Average earnings by nominal representation

\begin{tabular}{lcc}
\hline Local market & \multicolumn{2}{l}{ Average earnings in ECUS } \\
\cline { 2 - 3 } & All periods & Last five periods \\
\hline M100 & 1249.95 & 1094.94 \\
& $(1800.86)$ & $(1768.14)$ \\
M20 & 1309.54 & 1588.42 \\
& $(1539.34)$ & $(1699.70)$ \\
M5 & 2066.02 & 2111.40 \\
& $(2032.66)$ & $(2186.30)$ \\
\hline
\end{tabular}

\subsection{Payoff analysis}

In our experiment, aggregate profits across different nominal representations (Table 5) reveals profits in excess of the profits from Pareto superior Nash equilibrium (which is 1000) across the different nominal representations, with an increasing pattern. Table 10 in the Appendix shows that earnings in M5 are significantly and substantially above earnings in M20 and M100, while differences between M20 and M100 are significantly different in the last 5 periods (using individual period earnings as the dependent variable, and clustering standard errors by market).

Result 4 Profits to players increase with the nominal exchange rate.

\section{Alternative explanations: QRE, level-k, focal points and coarse grid Nash equilibrium}

In this section, we seek to understand the permanent nature of the nominal illusion, with players consistently choosing larger prices the larger the nominal exchange rate.

Figure 3 captures graphically this phenomenon. It depicts the average market price in ECUs, per nominal representation, for the first and the last block of five rounds, together with the $95 \%$ confidence interval. As it can be clearly seen, there is an increasing sequence of average market prices between nominal representations as larger exchange rates are considered but there are no significant differences in average prices within local markets between the first and the last block of five rounds. ${ }^{10}$

Why is this happening? One possible explanation is that because price competition with quadratic costs has multiple Nash equilibria, it follows from the Folk Theorem that it is possible to sustain in the finitely repeated game as a subgame perfect Nash equilibrium, prices that are not Nash equilibrium of the stage game. This would be true for each and all nominal representations, so this would not explain why different equilibrium prices will be selected in different local markets, as we observe in the laboratory.

In the literature, there is a number of alternative models to perfect rationality that have been proposed to account for deviations from the Nash prescription. Two popular

10 Figure 6 in the Appendix plots prices in all blocks across nominal representations. 


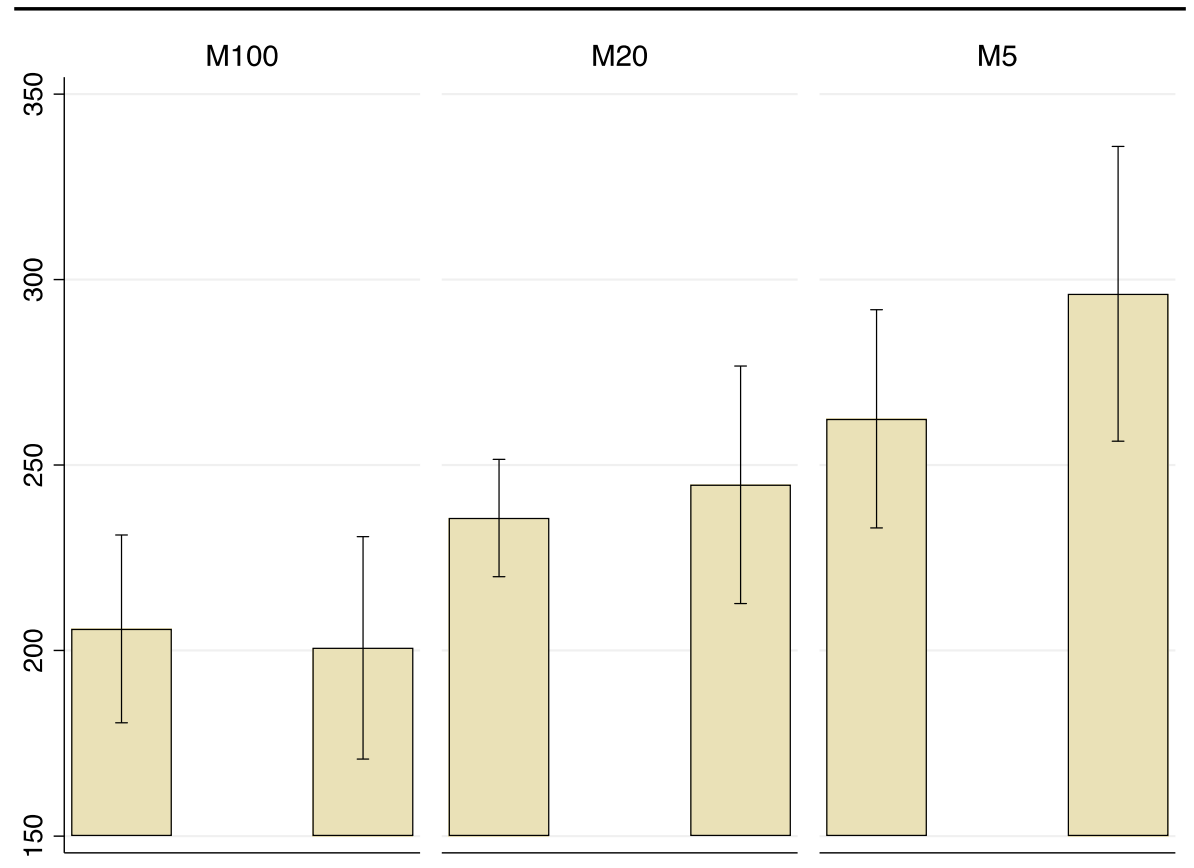

Fig. 3 Market prices in blocks of 5 rounds (in blocks of five rounds, first and last block)

candidates are quantal response equilibrium (QRE, McKelvey and Palfrey 1995, 1998) and level- $k$ (Stahl and Wilson 1994, 1995). It is easy to verify that none of these models can explain the monotone money illusion effect observed in our experiment. The reason is that both are reminiscent of the Nash concept and rely on computing best responses (mutual noisy best responses for QRE and perfect best responses, but with wrong beliefs, for level- $k$ ) using payoffs in real terms. So, the only possibility for these models to explain the (monotone) money illusion is assuming different values of their free parameter for different nominal representations. For the QRE, the free parameter is the noise parameter, and it is awkward to assume that different exchange rates prompt different values of the noise parameter.

For the level-k model, the free parameter is the belief that a level-1 type holds about the behaviour of level-0 (as higher types will stay arbitrarily close to the level1 choice because of the undercutting nature of the price competition game). ${ }^{11}$ So, unless level-1 types hold different beliefs about level-0 players for different values of the exchange rate, this model cannot account for the monotone money illusion effect. This assumption would be less ad hoc than in the QRE case, as it has been shown elsewhere (Hargreaves Heap et al. 2014) that the behaviour of level-0 types is not portable, but the criteria for the behaviour of level-0 types cannot be based on properties of the payoff matrix, such us payoff dominance, risk dominance, etc....

\footnotetext{
11 Level-k models tend to fit the data best in one shot interactions. Fatas and Morales (2013) is an example of behaviour consistent with a step-thinking model in the long run of 20 repetitions, as in our experiment.
} 
because as the local economies are equivalent in real terms, a level-0 type would behave in the very same way in all of them. ${ }^{12}$

Both alternative explanations were already considered and ruled out in Fatas et al. (2014) when they came to explain experimental price competition. Fatas et al. (2014) proposed an alternative model based on the concept of Coarse Grid Nash Equilibrium, which outperformed both QRE and Level- $k$. Here, we use this concept to rationalize the monotone money illusion effect and see how our dataset fits our conjecture.

The starting point is the observation that if players replace the (complex) continuous strategy set for a simpler object, a discrete version based on a coarse grid, then the set of Nash equilibrium prices in a duopolistic price competition with quadratic costs associated with players using a grid of size $k$ is the corresponding discretization of the Nash interval plus the first two multiples of $k$ larger than the Pareto efficient equilibrium. They call this set Coarse Grid Nash Equilibrium. ${ }^{13}$

From an outside observer, not aware of the discretization process performed by experimental subjects, these two "additional" equilibrium prices would be examples of players coordinating on high non-equilibrium prices. Because they will play a key role in our analysis, we will refer to them as "above-Nash equilibria".

As the primitives of the coarse equilibrium are grids, we need to say something about the process by which players discretize the strategy set across different nominal representations. We assume that the set of grids is invariant to the nominal representation.

Behavioural assumption The grid does not depend on the units.

This assumption says that the discretization process is independent from the nominal representation of the economy. Players do not consider that the different nominal representations where they may compete represent the same economy; they always perform the discretization process using the same set of grids. This assumption is in fact reminiscent of the numerosity heuristic (Pelham et al. 1994). This heuristic emerges when people fail to consider the type of unit when evaluating numerical information, and instead, they rely on the number of units. ${ }^{14}$

To see the consequences of this assumption, we fix a grid size $k$ and compare the set of coarse grid Nash equilibrium prices across different nominal representations of the economy. Consider a local market with exchange rate $e$. Let $c_{e}^{*}$ denote the production

\footnotetext{
12 An interesting alternative would be to assume that a level-0 type chooses prices per some focality criterion; in this alternative scenario, individuals would choose different prices in different local markets. We will explore later this possibility.

13 We can find in the literature studies about individuals using finite states when processing information by partitioning information or coarsening information, including Rubinstein (1993) or Chen et al (2010).

14 There is wide evidence of the use of the numerosity heuristic in psychological research. In consumption situations, decision makers perceive differences when information is communicated using different units. For example, Wertenbroch et al (2007) report differences in consumption when monetary differences are reported in different currencies, and Pandelaere et al (2011) report different behaviour when information is provided in small units (months) rather than large units (years).
} 
cost expressed in the local currency. The set of coarse grid Nash equilibria expressed in the local currency is ${ }^{15}$

$$
\begin{aligned}
\operatorname{CGNE}_{e}(k)= & \left\{\frac{1}{2} c_{e}^{*} Q, \frac{1}{2} c_{e}^{*} Q+k, \frac{1}{2} c_{e}^{*} Q+2 k, \ldots, \frac{3}{2} c_{e}^{*} Q\right\} \\
& \cup\left\{\frac{3}{2} c_{e}^{*} Q+k, \frac{3}{2} c_{e}^{*} Q+2 k\right\}
\end{aligned}
$$

By multiplying by the exchange rate $e$ and using $e \times c_{e}^{*}=c$, we can express the set of coarse grid Nash equilibrium prices in ECUS. We denote this set by $E P_{e}(k)$.

$$
\begin{aligned}
\mathrm{EP}_{e}(k) & =e \times \operatorname{CGNE}_{e}(k) \\
& =\underbrace{\left\{\frac{1}{2} c Q, \frac{1}{2} c Q+e k, \frac{1}{2} c Q+2 e k, \ldots, \frac{3}{2} c Q\right\}}_{D N E_{e}(k)} \cup \underbrace{\left\{\frac{3}{2} c Q+e k, \frac{3}{2} c Q+2 e k\right\}}_{A N_{e}(k)}
\end{aligned}
$$

The set of coarse grid Nash equilibrium $\mathrm{EP}_{e}(k)$ is the union of two sets. The first one, denoted by $\mathrm{DNE}_{e}(k)$, is the discretization of the Nash interval of the continuous price game. This set reveals how the grid size $k$ interacts with the nominal representation to produce the set of coarse grid equilibria: the effective grid size is augmented by a factor of $e(k \times e)$. This immediately implies that coarse grid equilibrium is not immune to nominal illusions, but the impact of the nominal changes is rather limited as it reduces to picking different (and fewer) elements from the Nash interval. The second set $\mathrm{AN}_{e}(k)$ is more interesting. It comprises the two above-Nash equilibria and the crucial issue is that they grow unbounded as the exchange rate increases (because the effective grid size $k \times e$ increases with $e$ ).

Because the above-Nash equilibria grow unbounded, there is a positive relationship between nominal changes and equilibrium prices. We call this concept monotone nominal illusion, define it in terms of the strong set order (because of the multiplicity of equilibrium prices) and prove that in fact, coarse grid Nash equilibrium displays monotone nominal illusion.

Definition 1: Monotone Nominal Illusion: Fix grid $k$. For every $e>0$ there exists $\hat{e}>e$ such that $\mathrm{EP}_{e^{\prime}}(k) \geq_{s} \mathrm{EP}_{e^{\prime}}(k)$ for $e^{\prime}>\hat{e}$.

Our proposition comes.

\section{Proposition 1: Coarse grid Nash equilibrium displays monotone nominal illusion.}

Proof Fix grid k and consider nominal exchange rate e. We divide the proof in two steps. Step (i) Let e be such that the effective grid size $e k$ is larger or equal than the efficient NE $\frac{3}{2} c Q$. This implies that $\operatorname{DNE}_{e}(k)=\emptyset$ and $\operatorname{AN}_{e}(k)=\{e k, 2 e k\}$. Let $\hat{e}=2 e$. Then we have $\operatorname{DNE}_{\hat{e}}(k)=\emptyset$ and $\mathrm{AN}_{\hat{e}}(k)=\{2 e k, 4 e k\}$, it follows that $\operatorname{AN}_{\hat{e}}(k) \geq_{s} \mathrm{AN}_{e}(k)$ which implies that $\operatorname{AN}_{e^{\prime}}(k) \geq_{s} \operatorname{AN}_{e}(k)$ for $e^{\prime}>e$ because the collusive equilibria are increasing in the exchange rate. Step (ii) Let $e$ be such that

\footnotetext{
15 To ease the exposition, we have assumed that the Pareto inferior and the Pareto efficient Nash equilibrium prices of the nominal representations are multiples of $k$.
} 
Table 6 Exchange rate, rounding and integer pricing

\begin{tabular}{llll}
\hline & \multicolumn{2}{l}{ Nominal representation of the economy } & \\
\cline { 2 - 4 } & M100 & M20 & M5 \\
\hline Price range & {$[0.0,100.0]$} & {$[0.00,20.00]$} & {$[0.000,5.000]$} \\
$\begin{array}{l}\text { Nash-equilibrium interval } \\
\text { Decimal places allowed }\end{array}$ & {$[10.0,30,0]$} & {$[2.00,6.00]$} & {$[0.500,1.500]$} \\
$\begin{array}{l}\text { Rounding prices } \\
\text { \% Round prices }\end{array}$ & 1 & 2 & 3 \\
\% Non-Nash round prices & 79.69 & 74.17 & 83.13 \\
$\begin{array}{l}\text { Integer pricing } \\
\text { \% Integer prices }\end{array}$ & 55.42 & 65.83 & 73.95 \\
\% Non-Nash integer prices & 79.69 & 55.42 & 41.04 \\
\hline
\end{tabular}

Rounding means that the experimental subject has not exhausted the number of decimal places available

the effective grid size $e k$ is smaller than the efficient NE $\frac{3}{2} c Q$. This implies that the largest element of $\mathrm{AN}_{e}(k)$ is smaller than four times the efficient $\mathrm{NE}$, i.e. $6 c Q$. Let $\hat{e}=6 c q / k$. Then the effective grid size of nominal exchange rate is $\hat{e} \times k=6 c Q$ and we have $\operatorname{DNE}_{\hat{e}}(k)=\emptyset$ and $\operatorname{AN}_{\hat{e}}(k)=\{6 c Q, 12 c Q\}$ and it follows that $\operatorname{AN}_{\hat{e}}$ $(k) \geq_{s} \mathrm{DNE}_{e}(k) \cup \mathrm{AN}_{e}(k)$. cqd.

This proposition reads that larger equilibrium prices are associated with larger nominal exchange rates. And this in fact encapsulates the two main features of the experimental data and Fig. 3: (1) players choosing prices larger than Nash equilibrium prices the larger the exchange rate, and (2) the lack of convergence to the efficient Nash equilibrium.

In the following, we look for evidence on the use of coarse grid Nash equilibrium in our experiment. This is not a straightforward exercise as grids are not directly observable. We follow a two-step procedure. First, we make the case that experimental subjects discretize the strategy space and second, we define a proxy for the grid used in each local market.

Evidence of discretization can be found by analysing the rounding patterns, i.e. practices where experimental subjects do not use all decimal places available in their market when setting their posted prices.

Table 6 shows that the percentage of rounding behaviour is quite high and roughly similar across treatments: in around $80 \%$ of instances, subjects do not use all decimal places. Note also that the percentage of round prices above the Nash equilibrium interval increases with the exchange rate. Table 6 also displays information on integer pricing across nominal representations, which is a more demanding phenomenon than rounding, especially for nominal representation M5, where only five prices out of 5.000 are integers. Well, for M5, 41\% of posted prices are integers; the percentage is even higher for the other two treatments: $55.42 \%$ and $79.69 \%$ for M20 and M100, respectively.

Result 5 Experimental subjects discretize the strategy space. 
Table 7 Posted prices and grids. Panel data estimations

Robust standard errors clustered at individual level in parentheses $* * * p<0.01 ; * * p<0.05 ; * p<0.1$

\begin{tabular}{|c|c|c|c|c|}
\hline & (1) & (2) & (3) & (4) \\
\hline \multirow[t]{2}{*}{ Period } & $11.54 * *$ & $7.324 * *$ & $22.47 * *$ & $11.54 * *$ \\
\hline & $(4.556)$ & $(3.565)$ & $(9.980)$ & $(4.556)$ \\
\hline \multirow{2}{*}{$\begin{array}{l}\text { Period } \\
\text { squared }\end{array}$} & $-0.449^{* *}$ & $-0.298 * *$ & $-0.807 * * *$ & $-0.449 * *$ \\
\hline & $(0.181)$ & $(0.148)$ & $(0.306)$ & $(0.181)$ \\
\hline \multirow[t]{2}{*}{ M5 } & $85.42 * *$ & $90.66^{* * * *}$ & $94.39 * *$ & $89.81 * * *$ \\
\hline & (36.99) & (34.69) & $(37.17)$ & $(31.76)$ \\
\hline \multirow[t]{2}{*}{ M20 } & 7.239 & 32.33 & 27.87 & 26.10 \\
\hline & (27.07) & $(26.48)$ & $(27.88)$ & (22.69) \\
\hline \multirow[t]{2}{*}{ Grid (avg 5) } & $1.253 * *$ & - & - & - \\
\hline & $(0.536)$ & & & \\
\hline \multirow[t]{2}{*}{ Grid (avg 3) } & - & $1.057 * * *$ & - & - \\
\hline & & $(0.371)$ & & \\
\hline \multirow{2}{*}{$\begin{array}{l}\text { Grid (avg } \\
10)\end{array}$} & - & - & $1.002 * * *$ & - \\
\hline & & & $(0.387)$ & \\
\hline \multirow{2}{*}{$\begin{array}{l}\text { Grid (max } \\
5 \text { ) }\end{array}$} & - & - & - & $0.763 * * *$ \\
\hline & & & & $(0.162)$ \\
\hline \multirow[t]{2}{*}{ Constant } & $111.5^{* * *}$ & $124.3 * * *$ & 20.94 & $59.20 * *$ \\
\hline & (37.97) & $(32.80)$ & $(82.46)$ & $(28.60)$ \\
\hline \multirow[t]{2}{*}{ M5-M20 } & $78.176^{* *}$ & $58.329 *$ & $66.522 * *$ & $63.701 * *$ \\
\hline & $(31.548)$ & $(30.110)$ & $(33.543)$ & $(28.402)$ \\
\hline Observations & 1,200 & 1,360 & 800 & 1,200 \\
\hline $\begin{array}{l}R \mathrm{Sq} \\
\quad \text { (between) }\end{array}$ & 0.1179 & 0.1601 & 0.1439 & 0.2841 \\
\hline
\end{tabular}

We define as a proxy for the grids in a local market the adjustment of posted prices by experimental subjects, i.e. the changes in prices from one round to the next. The rationale for this approach is the following: conditional on subjects using grids, the coarser their (unobservable) grids, the larger their (observable) update in prices. As we are aware of the limitations of this imperfect measure, we will be particularly cautious when interpreting the results of the quantitative analysis.

Table 7 contains the panel data estimations of various econometric models where the dependent variable is the posted price of individual firms and the covariates are a quadratic specification for period, dummy variables for nominal representations M5 and M20 and different specifications of the proxy for grids. ${ }^{16}$

We use two different definitions for grids. The first three models use as the proxy for grids the average price adjustment, in absolute terms, the firm has done in the

\footnotetext{
16 Estimations with controls for past choices can be found in the Appendix, Table 11.
} 
first three, five and ten rounds, respectively. ${ }^{17}$ The fourth model uses the largest price adjustment in the last 5 rounds. Given that there are no reasons to expect participants to restrict themselves to single-increment changes in prices, and that participants may decide to keep prices constant from one round to the next, the average price adjustment is a reasonable proxy for differences in grids across markets. Beyond its limitations, this measure has three merits: first, it captures changes in prices, rather than absolute prices. Firms decreasing or increasing prices using the same Grids (i.e. price adjustments) while posting collusive or competitive prices are indistinguishable from this metric's perspective. Second, we hypothesize that firms will explore the market in the first rounds sometimes keeping the same price two consecutive rounds (i.e. without adjusting the price up or down), sometimes moving up or down in the strategy space (i.e. positive price adjustment). Our measure of grids does not depend on the frequency of positive adjustments. And lastly, we are agnostic on the heterogeneity of firms in any treatment. Market heterogeneity may happen because firms are sophisticated enough to post prices in a competitive manner, not being affected by the nominal representation of prices, or because they use different price adjustment schemes.

Table 7 confirms how posted prices differ across the different nominal representations, where the omitted market is M100. The dummy variables are positive and significantly different from zero, increasing in the sequence M20-M5 and the difference between the estimates of M5 and M20 is significant and positive. In all models, the estimate of the grid proxy is positive and significant, implying that grids play a significant role in how market prices are set, as larger market prices are associated with larger grids. This result is robust to different specifications for the proxy for grid.

Result 6 As predicted by the Coarse Grid Nash equilibrium, experimental markets with large grids are associated with large market prices.

One feature missing in the previous analysis is that both players should choose the same price in a coarse grid Nash equilibrium. Table 7 above focuses in the analysis of posted prices and cannot capture whether by being in one treatment all firms coordinate more easily above competitive levels (again, a treatment effect), or whether only those firms choosing larger grids can sustain symmetric prices above Nash (a grid effect). In Table 8, we use as dependent variable a categorical dummy variable identifying those instances in which firms choose identical prices above Nash Equilibrium prices, i.e. above 150 . Whenever prices, above or below Nash, are not symmetric, the dependent variable takes the value of 0 . Table 8 below displays the marginal effects of three probit models.

We find that coordination on high prices increases with time, as the estimate for the variable period is significant and positive in models (1) and (2), being the effect insignificant in the second half of the experiment, model (3). We also find that the probability of collusion is higher in treatment M5 than in M100 - the omitted nominal representation- and smaller in local market M20 than in M100. As in Table 7, symmetric pricing is significantly more likely in markets with larger grids, as the positive and significant coefficient of variable grid in models (2) and (3) show.

\footnotetext{
17 This explains why the number of observations in the econometric estimation decreases with the number of rounds used to compute the proxy for the grid.
} 
Table 8 Probability of price coordination above Nash Equilibrium prices (Probit, marginal effects)
Robust standard errors in parentheses

$* * * p<0.01 ; * * p<0.05 ; * p<0.1$

\begin{tabular}{llll}
\hline & $(1)$ & $\begin{array}{l}(2) \\
(t>5)\end{array}$ & $\begin{array}{l}(3) \\
(t>10)\end{array}$ \\
\hline Period & $0.0338^{* * *}$ & $0.0493^{* *}$ & 0.114 \\
& $(0.00814)$ & $(0.0223)$ & $(0.0775)$ \\
Squared period & $-0.00120^{* * *}$ & $-0.00175^{* *}$ & -0.00385 \\
& $(0.000355)$ & $(0.000836)$ & $(0.00249)$ \\
M5 & $0.0655^{* *}$ & $0.130^{* * *}$ & $0.148^{* * *}$ \\
& $(0.0270)$ & $(0.0392)$ & $(0.0512)$ \\
M20 & $-0.107^{* * *}$ & $-0.111^{* * *}$ & $-0.0877 * *$ \\
& $(0.0213)$ & $(0.0289)$ & $(0.0407)$ \\
Grid & & $0.00188^{* * *}$ & $0.00189 * *$ \\
& & $(0.000661)$ & $(0.000869)$ \\
Predicted & 0.1018 & 0.1296 & 0.1521 \\
M5-M20 & $1.051^{* * * *}$ & $1.147 * * *$ & $0.970 * * *$ \\
& $(0.173)$ & $(0.192)$ & $(0.213)$ \\
Pseudo $R$-squared & 0.1020 & 0.0954 & 0.0771 \\
Observations & 800 & 600 & 400 \\
\hline
\end{tabular}

Result 6 Symmetric equilibrium profiles depend on the use of grids.

\section{Conclusions}

In this paper, we report the results of an exploratory study of money illusion, defined as the human tendency to make economic decisions on the basis of nominal rather than real variables. As such, nominal illusion may lead economic agents to making wrong choices, generating substantial but temporary welfare losses. The rationale behind this transitory effect is that agents will eventually see through the nominal veil, and will discover the incentives to best respond, amending their errors.

In this paper, we follow a very different route and show that nominal illusion can be a phenomenon that far from being transient, does not decay over time. Following Fehr and Tyran (2001, 2008), we study a coordination game with multiple equilibria and strong complementarities. Participants in our experiment first face a one-shot entry game where choose a local market to enter and compete in prices. Local markets are different nominal representations of the same real economy, with the same potential profits (and secondary differences in the number of decimals they can use to post prices). Despite we let subjects self-select into one of the three local markets, they allocate themselves in equal numbers across the local markets, consistent with the idea that they do conceive all nominal representations as payoff-equivalent in real terms (at least ex-ante). However, the pricing dynamic reveals an interesting pattern that becomes statistically significant for large enough nominal exchange rates: larger prices associated with larger nominal exchange rates, consistent with a monotone nominal illusion effect. 
The money illusion we document in this paper is consistent with results found in one-shot individual decision making studies. Raghubir and Srivastava (2002) study the salience of the nominal representation when individuals are requested to make spending decisions in an unfamiliar foreign currency, and find that consumers underspend when the face value of a foreign currency is a multiple of an equivalent unit of a home currency (e.g., 4 Malaysian ringgits p 1 U.S. dollar) and overspend when it is a fraction (e.g., 1 Bahraini dinar p 2.65 U.S. Dollar).

As the interesting feature of the monotone nominal illusion in our experiment is that it may persist over time, we propose a mechanism explaining persistence: if economic agents start focusing on the nominal representations because they are simpler and more salient (as it is the standard view in the literature, see Shafir et al. 1997) and they keep using them because it is a very profitable strategy, then market forces may be simply perpetuating collusive practices. We operationalize this intuition by offering a behavioural model that characterizes nominal illusion in a simpler and powerful way: we assume players explore and simplify the choice set by thinking on multiples of convenient numbers. Our model then let players follow a standard equilibrium logic, best responding to other players.

Our results are consistent with this intuition. The over-competitive behaviour has a 'discrete' crucial element: those firms exploring the strategy space in larger price adjustment intervals in the first five rounds of the experiment, maintain over-competitive prices in the last five periods, firms using smaller grids do not. Coordination above Nash equilibrium prices follows a similar logic. This intuitive approach shows that in frictionless markets, prices may stay above competitive markets because there are no incentives to deviate from any equilibria, once reached. By reconciling the logic of rationality, as captured by mutual best responses, with the existence of well documented behavioural biases, as nominal illusions, our results show how convergence to competitive solutions, as in the standard Bertrand-Nash equilibrium, may be slow, or may never happen.

One possible limitation of our analysis is the endogenous nature of entry decisions. Future analysis might investigate whether the monotone nominal illusion effect is also observed when experimental subjects are asked to compete in different nominal representations.

Acknowledgments The authors acknowledge the comments made by two anonymous referees that helped us improve the paper.

Funding Antonio J. Morales acknowledges financial support from research project RTI2018-097620-B-I00. Enrique Fatas acknowledges financial support from the ESRC Network for Integrated Behavioral Science (NIBS).

Availability of data and material The authors will share the experimental data upon request.

\section{Declarations}

Conflict of interest The authors declare that they have no conflict of interest. 
Human and animal rights This article does contain an experimental study with human participants. Participation was voluntary, and no experimental subject was harmed in any way. Their tasks involved sitting in a computer terminal and responding to questions of economic nature. They were paid in money.

\section{Code availability (software application or custom code)}

The authors will share the Stata code upon request.

Open Access This article is licensed under a Creative Commons Attribution 4.0 International License, which permits use, sharing, adaptation, distribution and reproduction in any medium or format, as long as you give appropriate credit to the original author(s) and the source, provide a link to the Creative Commons licence, and indicate if changes were made. The images or other third party material in this article are included in the article's Creative Commons licence, unless indicated otherwise in a credit line to the material. If material is not included in the article's Creative Commons licence and your intended use is not permitted by statutory regulation or exceeds the permitted use, you will need to obtain permission directly from the copyright holder. To view a copy of this licence, visit http://creativecommons.org/licenses/by/4.0/.

\section{Appendix 1: Additional quantitative analysis and figures}

See Fig. 4, 5, 6 and Tables 9, 10, 11.

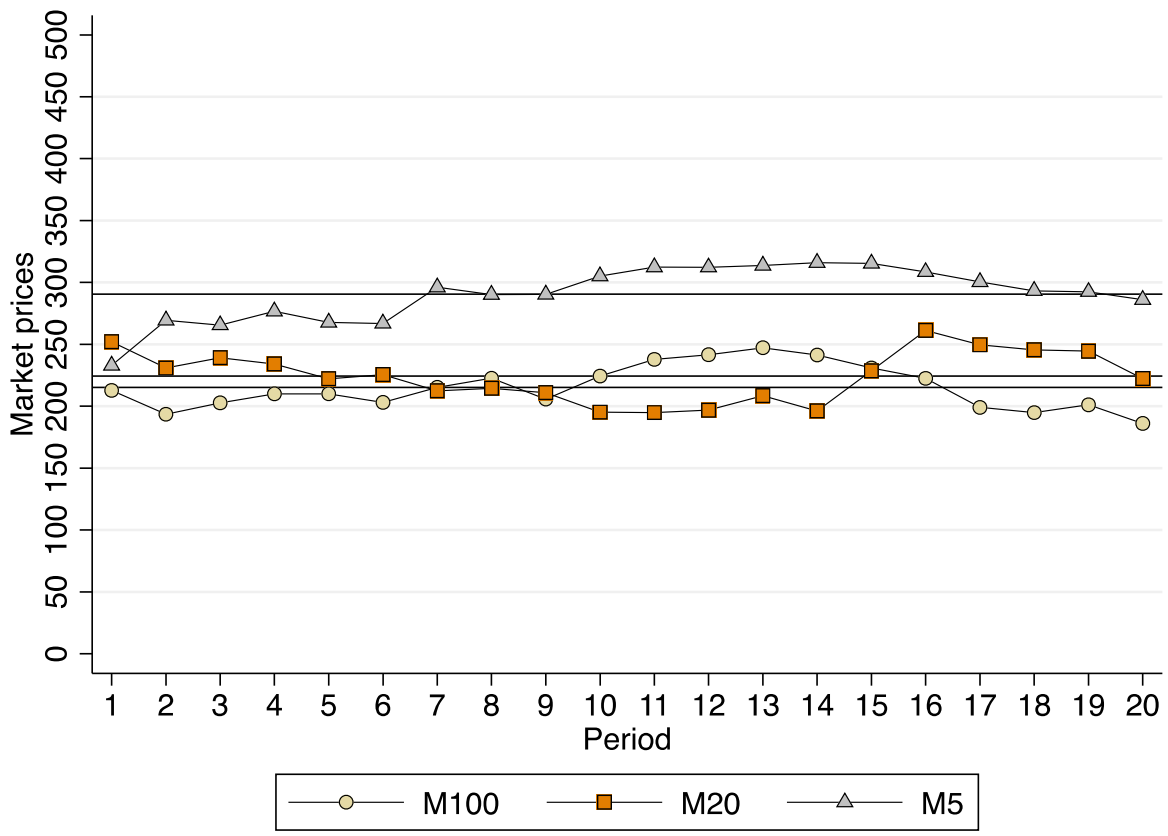

Fig. 4 Evolution of market prices in ECUs by nominal representation (all periods) 


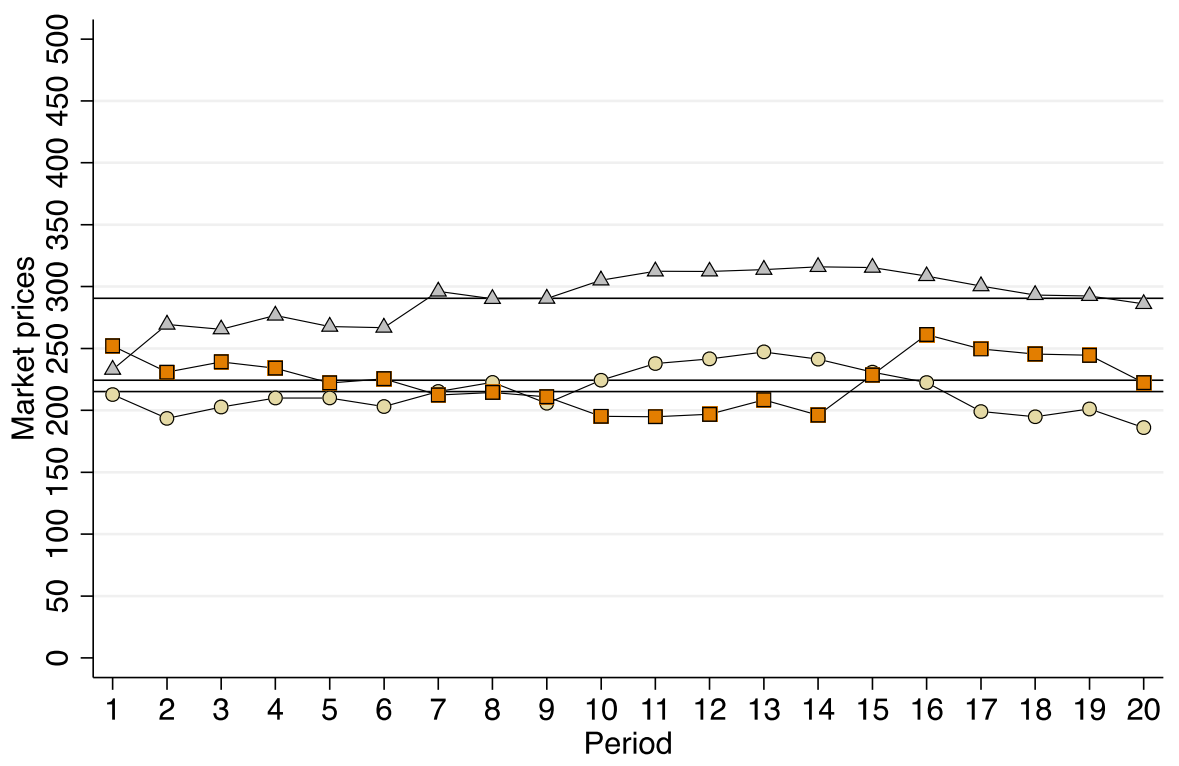

$\begin{array}{rllll}\square & \text { M100 } & \square\end{array}$

Fig. 5 Market prices (in blocks of 5 rounds)
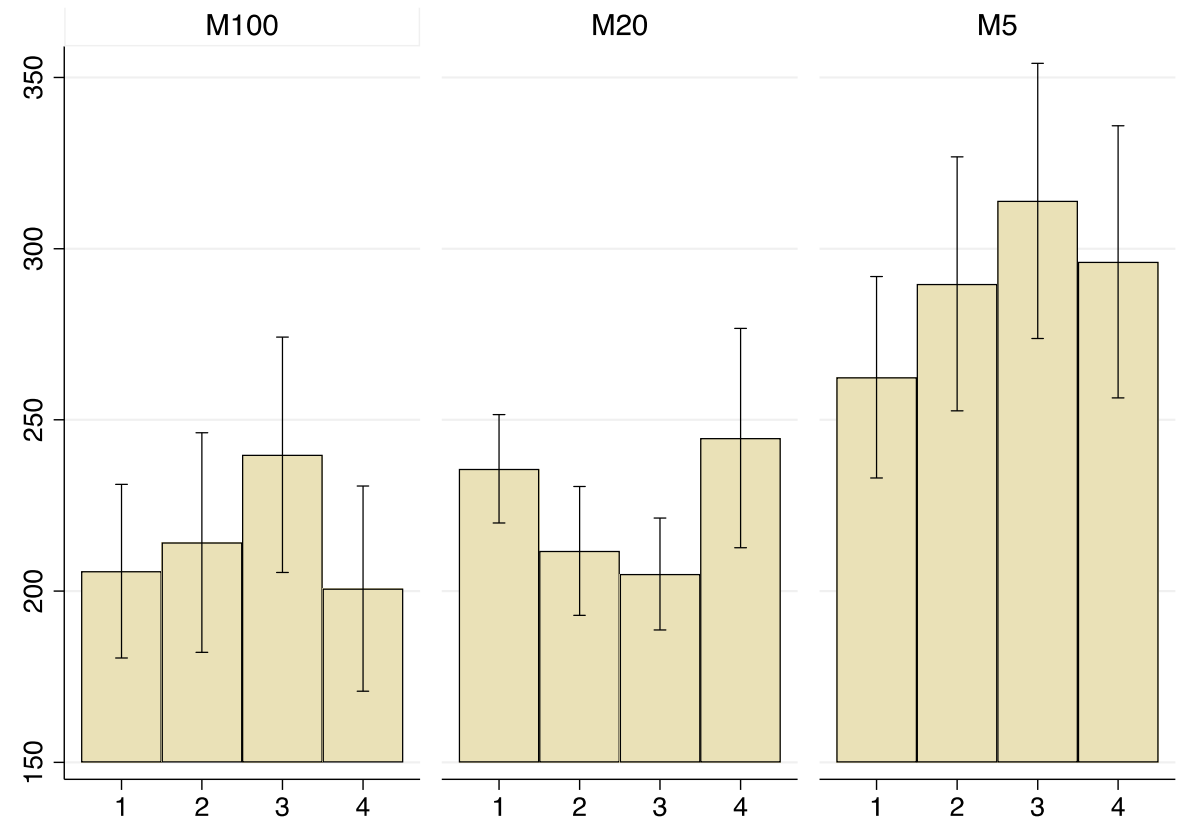

Fig. 6 Market prices in blocks of five rounds 
Table 9 Posted prices across nominal representations comparing M20 vs M5 (omitted treatment). Panel data estimations

\begin{tabular}{llllll}
\hline & $(1)$ & $(2)$ & $(3)$ & $(4)$ & $(5)$ \\
\hline Period & 1.010 & -0.965 & $3.696^{* * *}$ & $3.700^{* * *}$ & $2.862^{* *}$ \\
& $(2.324)$ & $(2.080)$ & $(1.245)$ & $(1.198)$ & $(1.215)$ \\
Period squared & -0.0559 & -0.0120 & $-0.166^{* * *}$ & $-0.167^{* * *}$ & $-0.140^{* * *}$ \\
& $(0.106)$ & $(0.0936)$ & $(0.0534)$ & $(0.0507)$ & $(0.0515)$ \\
M20 & $-57.43^{* *}$ & -27.57 & $-10.45^{* *}$ & $-6.341^{*}$ & -3.738 \\
& $(29.06)$ & $(22.95)$ & $(4.532)$ & $(3.449)$ & $(3.437)$ \\
M100 & $-67.05^{* *}$ & $-53.79^{* *}$ & $-11.53^{* *}$ & $-6.814^{*}$ & $-7.919^{* *}$ \\
& $(34.12)$ & $(23.97)$ & $(5.276)$ & $(3.865)$ & $(3.597)$ \\
Collusion in $t-1$ & & $171.9 * * *$ & & & $31.15^{* * *}$ \\
& & $(16.17)$ & & & $(6.894)$ \\
Own price in $t-1$ & & & $0.891^{* * *}$ & $0.534^{* * *}$ & $0.500^{* * *}$ \\
& & & $(0.0217)$ & $(0.0453)$ & $(0.0455)$ \\
Rival's price in $t-1$ & & & & $0.429 * * *$ & $0.401^{* * *}$ \\
& & & & $(0.0451)$ & $(0.0442)$ \\
Constant & $302.6^{* * *}$ & $278.8^{* * *}$ & $18.99^{* *}$ & -3.013 & $13.51^{*}$ \\
& $(23.74)$ & $(21.12)$ & $(8.598)$ & $(6.279)$ & $(7.526)$ \\
M20-M100 & 9.62 & 26.21 & 1.08 & 0.47 & 4.18 \\
$R$-squared (between $)$ & $(26.41)$ & $(20.70)$ & $(3.98)$ & $(3.77)$ & $(4.04)$ \\
Observations & 0.064 & 0.635 & 0.995 & 0.989 & 0.990 \\
\hline
\end{tabular}

Robust standard errors in parentheses

$* * * p<0.01 ; * * p<0.05 ; * p<0.1$

\section{Appendix 2: Experimental instructions}

1. This experiment lasts for 20 independent rounds (what happens in one round does not affect your results in any other round). Only for participating in the experiment, you guarantee a minimum payment of $€ 5$.

2. In this experiment, you are a firm that takes two types of decisions: the country where you sell your product and your selling price. Each market is composed of two firms. The first decision is taken only once at the beginning of the experiment, while the second is taken in each round. We will explain the consequences of these two decisions, starting with the second one.

3. The profits to your company are the difference between your revenues and your costs. Your revenues are your demand (the number of units sold) multiplied by your selling price (the price at which you sell). Your demand in each round depends exclusively on your decision (your selling price) and the decision of the other company in your market (the selling price of the other firm):

4. The market Demand in each round is fixed and the two firms offer exactly the same product. There are two possible scenarios: 
Table 10 Profits in ECUs across nominal representations. OLS estimations
(1)

\begin{tabular}{lll} 
& $(1)$ & $(2)$ \\
\hline Period & All periods & Last 5 periods \\
& 12.11 & -82.74 \\
M5 & $(7.837)$ & $(69.93)$ \\
& $816.1 * * *$ & $1016 * * *$ \\
M20 & $(116.8)$ & $(243.6)$ \\
& 59.59 & $493.5 * *$ \\
Constant & $(100.1)$ & $(208.6)$ \\
& $1123 * * *$ & $2584 * *$ \\
M5-M20 & $(105.5)$ & $(1277)$ \\
& $756.48^{* * *}$ & $522.98 * *$ \\
Observations & $(116.23)$ & $(252.38)$ \\
$R$-squared & 1600 & 400 \\
\hline
\end{tabular}

a) The two selling prices are equal. Then, the two firms equally share the demand.

b) The two selling prices are different. Then, the firm with the lowest price gets the whole market demand in that round and the other firm does sell nothing.

5. The cost function is increasing. This means that the cost of serving the market demand is more than the double than the cost of serving half of the market demand. Producing nothing incurs no cost. Independently of your company's market share, you are required to attend the market demand.

6. In a given round, you can obtain positive or negative profits which will be accumulated over the rounds, but if you end up with losses at the end of the experiment, these losses will never become effective. Every time you make a decision you will know the past values of prices and profits of the two firms in each round and your accumulated profits.

7. Your other decision is to choose the country where you wish to sell your product during the 20 rounds that the experiment lasts. In this experiment, there are 3 different economies: Titan. Methane and Daphne. The only difference between the three economies is the currency used in each country: Titanio (Ti), Metanio (Mt) and Daphnio (Df). Depending on which country you decide to sell your products, you must choose prices in the local currency.

8. If you decide to sell your product in Titan, you can choose a sale price between 0 and $100 \mathrm{Tt}$. If you decide to sell your product in Methane, your price should be between 0 and $20 \mathrm{Mt}$, and if you decide to sell at Daphne, your price should be between 0 and 5 Df. The number of decimal places that you can use varies in each market (1,2 and 3, respectively).

9. Once you choose the local economy in which you want to sell your product, you will be randomly paired with another participant who has chosen to sell its product in the same economy. For each economy, we will form independent markets of 2 firms each, whose composition will not change throughout the experiment. If the number of firms in a local economy is odd, one of them will be chosen randomly 
Table 11 Panel data estimations of posted prices with grids and controls

\begin{tabular}{|c|c|c|c|c|}
\hline & (1) & (2) & (3) & (4) \\
\hline Period & $\begin{array}{l}1.647 \\
(3.783)\end{array}$ & $\begin{array}{l}-0.561 \\
(2.782)\end{array}$ & $\begin{array}{l}5.093 \\
(10.68)\end{array}$ & $\begin{array}{l}2.268 \\
(3.741)\end{array}$ \\
\hline Period Squared & $\begin{array}{l}-0.234 \\
(0.148)\end{array}$ & $\begin{array}{l}-0.134 \\
(0.117)\end{array}$ & $\begin{array}{l}-0.402 \\
(0.323)\end{array}$ & $\begin{array}{l}-0.241 \\
(0.147)\end{array}$ \\
\hline M5 & $\begin{array}{l}38.80 * * \\
(16.29)\end{array}$ & $\begin{array}{l}44.26^{* *} \\
(18.14)\end{array}$ & $\begin{array}{l}18.72 \\
(12.98)\end{array}$ & $\begin{array}{l}40.83^{* *} \\
(16.74)\end{array}$ \\
\hline M20 & $\begin{array}{l}21.38 \\
(14.57)\end{array}$ & $\begin{array}{l}32.46 * \\
(16.77)\end{array}$ & $\begin{array}{l}19.41 \\
(12.66)\end{array}$ & $\begin{array}{l}26.94 * \\
(14.21)\end{array}$ \\
\hline Grid (avg 5) & $\begin{array}{l}0.751 * * * \\
(0.229)\end{array}$ & - & - & - \\
\hline Grid (avg 3) & - & $\begin{array}{l}0.393 * * \\
(0.183)\end{array}$ & - & - \\
\hline Grid (avg 10) & - & - & $\begin{array}{l}0.129 \\
(0.148)\end{array}$ & - \\
\hline Grid (max 5) & - & - & - & $\begin{array}{l}0.298 * * * \\
(0.0961)\end{array}$ \\
\hline Collusion in $t-1$ & $\begin{array}{l}164.6 * * * \\
(13.53)\end{array}$ & $\begin{array}{l}171.0 * * * \\
(14.80)\end{array}$ & $\begin{array}{l}152.1 * * * \\
(15.45)\end{array}$ & $\begin{array}{l}158.6^{* * *} \\
(14.18)\end{array}$ \\
\hline Cumulative earnings & $\begin{array}{l}0.00215^{* * *} \\
(0.000225)\end{array}$ & $\begin{array}{l}0.00178 * * * \\
(0.000225)\end{array}$ & $\begin{array}{l}0.00311^{* * *} \\
(0.000261)\end{array}$ & $\begin{array}{l}0.00190^{* * *} \\
(0.000261)\end{array}$ \\
\hline Constant & $\begin{array}{l}164.5^{* * *} \\
(24.65)\end{array}$ & $\begin{array}{l}186.8 * * * \\
(19.31)\end{array}$ & $\begin{array}{l}165.9 * * \\
(83.62)\end{array}$ & $\begin{array}{l}155.3 * * * \\
(23.42)\end{array}$ \\
\hline M5-M20 & $\begin{array}{l}17.412 \\
(16.080)\end{array}$ & $\begin{array}{l}11.796 \\
(17.817)\end{array}$ & $\begin{array}{l}-0.695 \\
(13.623)\end{array}$ & $\begin{array}{l}13.893 \\
(16.580)\end{array}$ \\
\hline Observations & 1200 & 1360 & 800 & 1200 \\
\hline$R \mathrm{Sq}$ (between) & 0.8500 & 0.8033 & 0.8877 & 0.8223 \\
\hline
\end{tabular}

Robust standard errors in parentheses

$* * * p<0.01 ; * * p<0.05 ; * p<0.1$

by the computer to compete in another local economy (and be warned of this). You will never get to know the identity of the participant with whom you are paired.

10. Demand and costs are identical in the 3 countries. However, the exchange rates that convert profits into Euros are different, so your potential benefits are also identical in the three economies. At the end of the experiment, the profits will be exchanged at the rate of $800 \mathrm{Tt}=160 \mathrm{Mt}=40 \mathrm{Df}=€ 1$. Your final profits will be the sum of the initial $€ 5$ plus the accrued profits over the 20 rounds. 


\section{References}

Achen CH (2000) Why lagged dependent variables can suppress the explanatory power of other independent variables. In: Annual meeting of the political methodology section of the American political science association, UCLA, vol. 20, No. 22

Acker D, Duck NW (2013) Do investors suffer from money illusion? a direct test of the modigliani-cohn hypothesis. Rev Finance 17:565-596

Bittschi B, Duppel S (2015) Did the introduction of the euro lead to money illusion? Empirical evidence from Germany. ZEW discussion paper 15-058

Brunnermeier MK, Julliard C (2008) Money illusion and housing frenzies. Rev Financ Stud 21:135-180

Buchan NR, Grimalda G, Wilson R, Brewer M, Fatas E, Foddy M (2009) Globalization and human cooperation. Proc Nat Acad Sci 106(11):4138-4142

Buchan NR, Brewer MB, Grimalda G, Wilson RK, Fatas E, Foddy M (2011) Global social identity and global cooperation. Psychol Sci 22(6):821-828

Cannon E, Cipriani G (2006) Euro-Illusion: a natural experiment. J Money Credit Bank 38:1391-1403

Chen Y, Iyer G, Pazgal A (2010) Limited memory, categorization, and competition. Mark Sci 29(4):650-670

Cohen RB, Polk C, Vuolteenaho T (2005) Money illusion in the stock market: the Modigliani-Cohn hypothesis. Q J Econ 120:639-668

Dufwenberg M, Gneezy U (2000) Price competition and market concentration: an experimental study. Int J Ind Organ 18(1):7-22

Eisenhuth R (2017) Money illusion and market survival. Macroecon Dyn 21:1-10

Fatas E, Mañez JA (2007) Are low-price promises collusion guarantees? An experimental test of price matching policies. SpanEconRev 9(1):59-77

Fatas E, Morales AJ (2013) Step thinking and costly coordination. Econ Lett 120(2):181-183

Fatas E, Georgantzís N, Máñez JA, Sabater-Grande G (2005) Pro-competitive price beating guarantees: experimental evidence. Rev Ind Organ 26(1):115-136

Fatas E, Georgantzís N, Máñez JA, Sabater G (2013) Experimental duopolies under price guarantees. Appl Econ 45(1):15-35

Fatas E, Haruvy E, Morales AJ (2014) A psychological re-examination of the Bertrand paradox. South Econ J 80:948-967

Fehr E, Tyran J-R (2001) Does money illusion matter? Am Econ Rev 91:1239-1262

Fehr E, Tyran JR (2007) Money illusion and coordination failure. Games Econ Behav 58:246-268

Fehr E, Tyran JR (2008) Limited rationality and strategic interaction, the impact of the strategic environment on nominal inertia. Econometrica 76:353-394

Fehr E, Tyran JR (2014) Does money illusion matter? Reply. Am Econ Rev 104:1063-1071

Fisher I (1928) Money illusion. Adelphi, New York

Hargreaves Heap S, Rojo Arjona D, Sugden R (2014) How portable is level-0 behavior? A test of level-k theory in games with non-neutral frames. Econometrica 82(3):1133-1151

Kahneman D (2003) Maps of bounded rationality: psychology for behavioral economics. Am Econ Rev 93:1449-1475

Kooreman P, Faber R, Hofmans H (2004) Charity donations and the Euro introduction-some quasi experimental evidence on money illusion. J Money Credit Bank 36:1121-1124

McKelvey RD, Palfrey TR (1995) Quantal response equilibria for normal form games. Games Econom Behav 10:6-38

McKelvey RD, Palfrey TR (1998) Quantal response equilibria in extensive form games. Exp Econ 1:9-41 Noussair C, Richter G, Tyran JR (2012) Money illusion and nominal inertia in experimental asset markets. J Behav Financ 13:27-37

Pandelaere M, Briers B, Lembregts C (2011) How to make a 29\% increase look bigger: the unit effect in option comparisons. J Consum Res 38:308-322

Pelham BW, Sumarta TT, Myaskovsky L (1994) The easy path from many to much: the numerosity heuristic. Cogn Psychol 26:103-133

Raghubir P, Srivastava J (2002) Effect of face value on product valuation in foreign currencies. J Consum Res 29:335-347

Rubinstein A (1993) On price recognition and computational complexity in a monopolistic model. J Polit Econ 101(3):473-484

Shafir E, Diamond PA, Tversky A (1997) Money illusion. Q J Econ 112:341-374 
Stahl DO, Wilson PW (1994) Experimental evidence on players' models of other players. J Econ Behav Organ 25(3):309-327

Stahl DO, Wilson PW (1995) On players' models of other players: theory and experimental evidence. Games Econom Behav 10:218-254

Thaler RH (2000) From homo economicus to homo Sapiens. J Econ Perspect 14(1):133-141

Tyran JR (2007) Money illusion and the market. Science 317:1042-1043

Wertenbroch K, Soman D, Chattopadhyay A (2007) On the perceived value of money: the reference dependence of currency numerosity effects. J Consum Res 34:1-10

Publisher's Note Springer Nature remains neutral with regard to jurisdictional claims in published maps and institutional affiliations. 